\title{
Application of Meta-cognitive Strategy in College English Teaching
}

\author{
Zhao Hui Min ${ }^{1, \text { a }}$ \\ ${ }^{1}$ Bohai university, Jinzhou, 121013 China \\ ahmzhao2008@163.com
}

\begin{abstract}
Keywords: Autonomous learning; Meta-cognition; College English teaching.
\end{abstract}
\begin{abstract}
Autonomous learning is the process that students acquire knowledge independently. It enables students to possess the ability of lifelong learning, which is the key point of current English education. The key important part of autonomous learning is the learning and implementation of meta-cognition. The level of meta-cognition determines the success or failure of autonomous learning. In this article, the author discusses the application of meta-cognitive strategies in College English teaching and puts forward some suggestions on it.
\end{abstract}

\section{Introduction}

As Chinese saying goes: 'delegate to fish in the fishery as delegate'. In the book of 'Learn to Survive', UNESCO once said: 'In the era of knowledge economy, the so-called 'illiterate' is no longer the people without mastering a certain scientific and cultural knowledge, but the people without the ability of acquiring the emerging knowledge.' Lifelong education has become the surviving concept and medium in the 21st Century. Learning how to learn and learning independently is recognized as the ideal goal of current education. Holec holds that autonomous learning is the ability to manage language learning[1]. Thomas believed that 'autonomy of learning is a kind of learning of students responsible for themselves.' Autonomous learning is the study of self-orientation, self-motivation and self-monitoring, which is an active, independent and meta-cognitive monitoring learning. Study shows that ability of autonomous learning is closely related to the meta-cognition. Training of meta-cognitive strategy plays an important role in improving meta-cognitive level, optimizing the learning mode and enhancing the self-monitoring ability and improving the academic performance of students. If students want to be successful learners, they must have autonomous learning ability. Meta-cognitive strategy is the bridge to autonomous learning and plays an important role in cultivating the learning autonomy. Therefore, College English teachers should pay much attention to training the meta-cognitive strategies and cultivating the autonomous learning ability of students.

\section{Meta-cognition}

Meta-cognitive strategy is the key to the cultivation of learner autonomy. Wenden once said that learners use meta-cognitive strategies to monitor, manager and control their own learning[2]. O. Malley once pointed out that students without meta-cognitive strategies are basically the persons without ability to assess their progress, grades and determining their future learning orientation[3]. Obviously, meta-cognitive strategy is a senior management method and tool that enables learners to take their learning responsibility. Meta-cognition includes three aspects. The first one is the meta-cognitive knowledge, that is, the knowledge about the individual's cognitive activities, processes and results. The second one is the meta-cognitive experience, which is generated in cognitive activities. The third one is the monitoring of meta-cognition, that is, individuals monitor their own cognitive activities and adjust to achieve the goal accordingly. In the actual cognitive activities, knowledge, experience and monitoring of meta-cognition are interrelated and mutually influenced and restricted by each other. The meta-cognitive process is the process of guiding and adjusting the cognitive process as well as the process of selecting and implementing the cognitive strategies. The essence is the self consciousness and self control of cognitive activity. Based on the meta-cognitive theory, Paris divides the knowledge of meta-cognitive strategies into three categories: 
declarative knowledge, procedural knowledge and conditional knowledge[4]. Declarative knowledge is the one about the facts. It explains the problem 'what it is', including the understanding of the factors that affect the learning. Procedural knowledge refers to the knowledge how to carry out the cognitive activities, e.g. the using of certain strategy. The conditional knowledge is to explain 'why', including the reason and when to use it. In short, the cognition of cognition is the process that the students acquire the knowledge on the factors affecting learning activities by introspection, taking their own learning activities as cognitive objects, and implement this knowledge to the learning process. Generally, meta-cognitive strategy can be divided into three types. The first is planning strategy, which includes setting up learning goals, viewing the reading materials and generating questions and analyzing how to complete the task of learning. Making learning plans is the important part of learning process. The second is monitoring strategy. Monitoring strategy includes tracking the hints when reading and questioning themselves and monitoring their own speed and time in examination. These strategies enable learners to be alert to problems of attention and understanding, find and correct them. We describe two specific monitoring strategies as follows. (i) Understanding monitoring. Readers with efficiency keep this process during the reading activities. They have the goal in mind, such as finding the detail or key points, etc. Then they read the text to achieve this goal. As the strategy is implemented, learners may find the important details and seize the key point. Then they will experience the feeling of satisfaction when they achieve the goal. If the monitoring shows that the target is not achieved, the learner will take remedial measures. (ii) Focus attention. Attention is a limited resource like energy resource and it can only be used for certain thing at some time. When the teacher asked the students to pay attention to the things they were undertaking, students had to give up the attention to other things. They have to transform the priority, and eliminate other stimulation completely. (iii) Regulatory strategy. Regulatory strategy is related to the monitoring strategy. For example, when the learner realizes that he does not understand certain part of the textbook, he will read the difficult passage again, slow down when reading a difficult material and review those courses they do not understand. Adjustment strategy can help students modify their learning behavior and remedy their understanding of the problem.

\section{Introduction of meta-cognitive strategy in English teaching}

Cultivation of meta-cognitive awareness and strategies aims to help students "learn how to learn" and make the students to become the dominators of learning. It is not enough to master a foreign language via classroom learning. It should depend on the much practice and hard self-study, including the process of continuing to learn after leaving school. Due to many drawbacks of current English language teaching, students have been influenced by the traditional teaching mode, which is teacher-centered, from primary school to middle school. There exists a serous examination-oriented tendency in English teaching, which results in the little opportunity of actively learning for students. Therefore, it is very important to cultivate the strategies of meta-cognition in College English teaching, which is important for current and future English learning of students.

Planning. Help students to make learning plans and set up learning goals. The environment of learning has changed and the learning style transfers from the middle school style to the autonomous learning after students are enrolled at college. Many students in college are very vacant and empty and have noting to do. They still stay in the old learning style of middle school, in which teacher gives the assignment each week. Therefore, teacher should help students transit from the learning style of middle school to the style of university. We have carried out an investigation of questionnaire on the learning situation of students. From the results of questionnaire, we suggest that students should be familiar with their own learning level and make learning plans according to individual situation. This plan can be accomplished by hard work and does not frustrate the student. Teacher should pay more attention to students' schedules of learning plans and help students manage their learning time.

Monitoring. Help students to monitor their learning process. It can help students to improve the ability of solving problems by strengthening the exercise of meta-cognitive strategies. Teacher should encourage students to write learning journal each day. The purpose is to promote students to 
reflect on their own learning process and clear ideas and put forward some valuable questions. This can encourage students to learn by themselves and produce important insights in learning process. It is helpful for students to take the initiative to manage their own learning and transfer their attention from the learning results to cognitive process. Regular reflection is also a good monitoring strategy. For example, we can guide students to reflect on the following questions: Do I understand and remember the contents of the study? What is the cause of this problem and which method can be used to solve it? What are my advantages when I finish the task? Which aspect of my performance needs improvement? What are the improvements in my communication strategies? Which aspect do I behave badly in?

Evaluating. Help students to assess the effect of learning. Generally, students in college have poor English level. We employ the hierarchical teaching and divide the students into several classes by considering the individual difference. We cultivate the students' self-evaluation ability via the following measures. Students in different class read different English reading materials. Teacher provides the web address to students and asks them to read online and test whether they make progress. Teacher gives students a standard test after finishing two units. Teacher asks students to conduct self-assessment and find the learning problems and adjust the original plan and goal. Teacher urges students to complete the self-assessment in the extension learning. This teaching mode has changed from the teacher-centered one to the student-centered one and enhances the self-confidence and learning motivation of students. Therefore, it is helpful to guide students to think and study independently. Meta-cognitive strategies always work together with cognitive strategies. If one does not have the desire and ability to make use of cognitive strategies, he will not succeed in planning, monitoring and self regulating. Cognitive strategy is an essential tool for learning English. Meta-cognitive strategy monitors and guides the implementation of cognitive strategy. Teacher can impart different strategies to students, however, if students do not use meta-cognitive skills to help themselves decide which strategy should be used in certain situation, they are not deemed to be successful learners.

\section{Conclusions}

Autonomous learning is the requirement of social and educational development as well as human subjectivity. It is a kind of survival and learning styles of modern people. Autonomous learning is a process of self monitoring, self guidance and self strengthening. Autonomous learning is actually monitored by meta-cognition. It is the process that learners actively adjust their learning strategies and efforts according to their own learning ability and task requirements. The ability of autonomous learning is closely related to meta-cognition and its strategies. Therefore, teacher should pay more attention to improve students' meta-cognitive ability and cultivate the meta-cognitive strategies, so that students can actively monitor their learning process and become successful autonomous learners.

\section{Acknowledgements}

This work is supported by Social Science Foundation of Liaoning Province (No. L15DWW005) and Bohai University Teaching Reform Project (No.BDJG15QNB002).

\section{References}

[1] H. Holec, Autonomy and Language Learning[M] . Oxford : Pergamen ,1981.

[2] A. Wenden, Learner strategies[J]. TESOL Newsletter, 1985, (19): 1-7

[3] J. M. O’Mally, Learning strategies used by beginning and intermediate ESL students[J], Language, 2006, 35(1):21-46 
[4] S. G. Paris, M. Y. Lipson, K. K. Wisxon, Becoming a strategic reader[J], Contemporary Educational Psychology, 1983, 8(3):293-316. 